\title{
EDUCATION
}

Strong emotions such as frustration, anger and hatred were associated with stress.

- Students whose test scores indicated that they had higher levels of emotional

intelligence (EI) used reflection and appraisal, social and interpersonal, and organisation

and time-management skills to cope with stress.

- Those with lower El scores engaged in health damaging behaviours such as smoking, drinking and risk taking.

\section{Emotional intelligence and stress coping in dental undergraduates - a qualitative study}

\author{
A. K. H. Pau ${ }^{1}$, R Croucher ${ }^{2}$, R. Sohanpal ${ }^{3}$, V. Muirhead ${ }^{4}$ and K. Seymour ${ }^{5}$
}

Objective: To explore how dental undergraduates with different levels of emotional intelligence (EI) cope with stress. Design: Qualitative unstructured depth interviews. Setting: A dental teaching hospital in the UK, 2002. Subjects and Methods: Subjects selected from the undergraduate population of a 5-year dental degree course. A questionnaire survey was carried out to determine the El scores of the subjects. In each year of study, subjects were divided into low and high El groups at the median score. From each El group in each year, one male and one female subject were recruited. Data collection Unstructured face-to-face interviews. Data analysisTranscribing, sifting, indexing and charting data according to key themes. Results: 10 males and 10 females with low and high El, representing all 5 years of study were interviewed. The experience of stress, expressed in emotional terms, ranged from anger and frustration to hatred. Four sets of coping strategies, adopted at varying degrees according to El, were identified. High El students were more likely to adopt reflection and appraisal, social and interpersonal, and organisation and time-management skills. Low El students were more likely to engage in healthdamaging behaviours. Conclusions: Future research needs to establish whether the enhancement of El in dental students would lead to improved stress-coping, and better physical and psychological health.

Stress in dental undergraduates has been widely reported in the literature. ${ }^{1-4}$ The ability to cope well with stress is important because stress can result in healthdamaging behaviours and psychological morbidity. ${ }^{5}$ Recent research indicates that psychological morbidity, ${ }^{6}$ pathological anxiety $^{7}$ and emotional exhaustion ${ }^{8}$ in dental students are not uncommon. Various strategies have been recommended for coping with stress in the dental environment ${ }^{9-12}$ although the degrees to which

\footnotetext{
${ }^{1 *}$ Lecturer in Dental Public Health, ${ }^{2}$ Professor of Community Oral Health, ${ }^{3}$ Research Assistant, ${ }^{4}$ Research Assistant, ${ }^{5}$ Senior Lecturer in Periodontology and Honorary Consultant in Restorative Dentistry, Centre for Oral Biometrics, Barts and The London, Queen Mary's School of Medicine and Dentistry, University of London, Turner Street, London E1 2AD

Correspondence to: Allan Pau

Email:a.k.pau@qmul.ac.uk
}

\section{Refereed Paper}

doi: $10.1038 /$ sj.bdj.4811573

Received 08.07.03; Accepted 13.10.03

( ) British Dental Journal 2004; 197: 205-209 different strategies are adopted and whether students with certain characteristics apply coping strategies better remain largely unexplored. The literature suggests that individuals with high optimism, defined as a generalised expectation of positive experiences and outcomes throughout one's life, make more extensive use of a variety of coping strategies, and have better physical and psychological health. ${ }^{13}$ In contrast, those with low selfesteem, defined as an individual's general sense of self value or worth, have been shown to experience greater negative stress $^{14}$ and use more withdrawal and passive forms of coping to manage stressful events. Whilst individuals with high optimism and self-esteem may appraise a stressful event as challenging rather than threatening, it has also been reported that stressful events can reduce self-esteem in individuals. ${ }^{13}$ Moderating between the perception of self-worth, and physical and psychological health may be the ability to appraise and manage stressful events, including the emotions that these events provoke or arouse. It has also been proposed that the ability to perceive emotions in self and others, manage them, and handle relationships are important attributes for health workers. They enable them to cope better with stress, thus contributing positively to health maintenance, including mental health, and career development. ${ }^{15}$ These attributes are encapsulated in the psychological construct called Emotional Intelligence (EI), recently popularised by Goleman. ${ }^{16}$

EI is conceptualised in terms of perception, appraisal and expression of emotion; emotional facilitation of thinking; understanding, analysing and employing emotional knowledge, and reflective regulation of emotions. ${ }^{17}$ Using the scale developed by Schutte et al. ${ }^{17}$ four factors have been identified: ${ }^{18-20}$

1. Optimism/mood regulation - the ability to maintain a positive emotional outlook 


\section{EDUCATION}

or to control emotions when under pressure, eg 'I use good moods to keep myself trying in the face of obstacles'.

2. Utilisation of emotions - the ability to use the emotional impact of major events to guide personal development, eg 'Some of the major events of my life have led me to re-evaluate what is important and not important'.

3. Appraisal of emotions - the ability to recognise and perceive emotions in self and others, eg 'By looking at their facial expressions, I recognise the emotions people are experiencing.

4. Social skills - the ability to empathise and relate with other people, eg 'When another person tells me about an important event in his or her life, I almost feel as if I have experienced this event myself'.

The EI construct focuses on a relatively limited set of skills and abilities, those dealing with people and emotions, when viewed in the context of a range of intelligences proposed by Gardner (1999) ${ }^{21}$ in his theory of multiple intelligences. In other words, other significant skills or intelligences are identifiable and may be usefully applied to achieve desirable outcomes. Although the prescriptions of those promoting EI in education have been challenged $^{22}$ (Carr, 2000) in some quarters of health care education, EI has also been recommended as a criterion for the selection of medical ${ }^{23}$ and nursing ${ }^{24}$ students, and proposed as an important attribute of professional competence. ${ }^{25,26}$ It has also been suggested that medical school physicians' EI is associated with patient satisfaction. ${ }^{27}$ The increasing interest in EI is in part due to suggestions that skills and behaviours associated with EI can be improved or developed (Watkin, 2000, Lynn 2002). ${ }^{28,29}$

EI is an attribute that may enable individuals to recognise and manage emotions evoked by stressful experiences. High EI individuals may apply coping strategies with more positive outcomes. This study aimed to explore, by using unstructured face-to-face interviews, how dental undergraduates with different levels of EI cope with stress in the dental environment.

\section{METHODS}

This study took place during Sept/Oct 2002, at the beginning of the academic year. The head of the dental school, the senior clinical tutor for student progress, the student president and students representing each year of dental course were informed of the study. Students were assured that they would not be identifiable from the interviews.

A purposive sampling approach ${ }^{30}$ was adopted to recruit 10 male and 10 female

\begin{tabular}{|c|c|c|c|c|}
\hline & \multicolumn{2}{|c|}{ Males } & \multicolumn{2}{|c|}{ Females } \\
\hline & Low El & High El & Low El & High EI \\
\hline Year 1 & 1 & 1 & 1 & 1 \\
\hline Year 2 & 1 & 1 & 1 & 1 \\
\hline Year 3 & 1 & 1 & 1 & 1 \\
\hline Year 4 & 1 & 1 & 1 & 1 \\
\hline Year 5 & 1 & 1 & 1 & 1 \\
\hline
\end{tabular}

students, representing those from low and high EI, and from different years of study (Table 1). This approach deliberately seeks out individuals that fit the cells in the sampling grid. Statistical representativeness was not sought. A range of different perspectives was incorporated to ensure that not any one viewpoint, which may possibly be the most common, is presented as if it represents the sole truth about a situation. ${ }^{31}$ As is usual in qualitative studies, sample sizes are not determined by hard and fast rules, ${ }^{32}$ and usually do not exceed 50 people.

In order to identify students with low and high EI, a questionnaire survey was first carried out to obtain the EI scores of all five years of undergraduates using the Schutte et al. ${ }^{15}$ EI scale. The results of this survey have been reported elsewhere. ${ }^{33} \mathrm{~A}$ total of 213 students (70\%) participated in this survey. For the purpose of this study, the sample was categorised into low and high EI groups at the median EI score according to their test scores on the Schutte et al. scale, although this classification may be perceived to be unfair on the basis of one test. From each EI group in each year of study, one male and one female student was recruited until all the cells in the sampling grid (Table 1) were filled. Recruitment began by approaching volunteer students with the lowest and highest EI scores in each year until all the cells in the sampling grid were filled.

Two freelance dentally qualified researchers who were not part of the teaching staff conducted the interviews. Both interviewers were blinded to the EI score of the interviewees. Before the interviews commenced, the interviewers were briefed and trained by the lead researchers (AKHP and RC) who are experienced in qualitative research. The interviews took place in a private office within the dental teaching hospital. Each interview was audio-taped. The duration of the interviews ranged from 45 to 60 minutes. The interviewers explained to interviewees that the purpose of the study was to find out how different students experience stress in the dental training environment and how they cope with their stress. Students were assured of confidentiality and the availability of counselling support offered by the college student counselling service should any difficult issue arise. The interviewers' names and telephone numbers were given to participants to allow the opportunity for any future queries about the study. Permission was sought from participants to record the interviews. A topic guide based on the following research questions were used:

1. Have you experienced any stress lately? 2. Have you felt any (strong emotions: anger, frustration, anxiety...) lately?

3. What has it been like to be stressed/ angry/frustrated/anxious...?

4. How have you responded/coped with your stress/emotions?

The interviewees were encouraged to determine the pace and direction of each interview. The interviewers listened to the interviewees' description of their experiences of stress, intervening to clarify the information offered and taking the interview forward when necessary.

Each interview was audio-recorded, transcribed and analysed using 'Framework' ${ }^{34}$ The recordings were listened to twice to allow familiarisation of the material and to develop a thematic framework by the interviewers. This involves systematically sifting, indexing and charting the transcribed data according to key issues and themes. Salient comments were extracted from the transcripts. The salient comments were indexed according to the thematic framework that had been developed. Next, half the transcriptions were reviewed and indexed independently by the two lead researchers (AKHP and RC). Following this, the research team reviewed and discussed the data to refine the thematic framework. The indexed data were then sorted according to the various individual themes. Salient comments from all students on each theme were next charted to identify any distinctive patterns or characteristics. To ensure transparency of the analysis process, the preliminary findings were next presented in a seminar to a representative from the funding 
body and the head of the dental school. Their comments and feedback were taken into account in the refining of the final thematic framework.

\section{RESULTS}

All the cells in the sampling grid were filled. Twenty students, 10 male and 10 female, representing all five years of study and with low and high EI were interviewed. Most of the interviewees reported that they had experienced some degree of stress. The experiences of stress were expressed in emotional terms. The emotions expressed ranged from anger and frustration to hatred.

'I feel...anger, frustration...because of forces outside your control...You just have to work your way round it...Perhaps you think on the spot...no fast handpiece but a reduction handpiece maybe...' (M5HighEI : male 5th year high EI)

'...the whole system makes me angry...the booking system...a joke...the equipment is so lacking...lack of organisation...I just hate it...I hate dentists...' (M5LoEI)

Four sets of coping strategies were identified. These were named reflection and appraisal, social and interpersonal skills, lifestyle or behavioural adjustments, and organisation and time-management skills.

\section{Reflection and appraisal}

Most of the interviewees were aware of their emotions and were able to describe them. Whilst all were able to reflect on their emotions, high EI students were more likely than low EI students to appraise their emotions in rational and constructive terms.

‘... get apprehensive...a little nervous...before seeing a patient...it's just the way you work yourself up to it...' (M4HighEI)

'...my first Conservative patient...patient must be anxious...I was quite anxious myself...so it would be nice for the tutor to sit down and talk it through with me...' (F3HighEI)

Low EI students tended to reflect negatively on their stressful experiences:

'...some people look at me...you know...like really disgusted...I feel really patronised by some students...' (4MLoEI)

'...you shouldn't leave the patients, but when you are queuing up for the tutor...the patient feels as if you are unorganised and they are sort of looking at you when it's not your fault...' (F4LoEI)

\section{Social and interpersonal skills}

Interviewees expressed how they responded to stressful experiences in relation to their peers, social network and families. Varying degrees of social and interpersonal skills were displayed in accessing social and family support. A trend in the use of social support to cope with stress was recognised according to the EI scores of the interviewees. Low EI students showed a lack of social and interpersonal skills in their use of social support.

Typically, low EI students did nothing or procrastinated,

'...I mean, I think about it...and concentrate on something else...watch television...' (F2LoEI)

'...I don't want to speak...kind of like look down...and walk to my room...sit for a little while...' (F5LoEI)

\section{rejected their social network,}

'...I have a professional relationship with people I work with in dentistry but I don't think I have anything in common with them other than dentistry...' (M3LoEI)

'...it's just like everybody and everything gets on your nerves, ....you are like, keep out of my sight.... got into trouble with my flatmate.' (F3LoEI)

or did not believe that they could rely on their social network to help them cope with their stress,

'... a problem shared is a problem halved...but it doesn't really work like that. So in the end I sit right back...try to address all the things that are stressing me out...' (M4LoEI)

'...I don't tell my friends when I've got problems because...I don't like whinging about things...' (M5LoEI)

High EI students on the other hand reinforced their need for social support to cope with their stress,

'...if anything would help...I'd say support and going home...' (F3HighEI)

demonstrated social skills in accessing social support,

'...if I am really stressed out, I go and talk to someone...talk to friends...I find it quite easy talking...but there are also times when no one can understand... a very personal experience...' (M5HighEI)

'...I have to say my friends help me a lot...because they go through these similar things...' (F4HighEI)

and were assertive and used interpersonal skills in addressing the sources of their stress,

'...I just don't think I get angry a lot...if something irritates me then I'll say something about it...' (F4HighEI)

'...if someone upsets me...I would confront...go up to them and ask them if there was anything wrong...I'd like to know...' (F3HighEI)

Interviewees also reported lifestyle or behavioural adjustments when coping with stress. These were typically health-damaging behaviours such as smoking, drinking or taking risks. There was a differentiation in the adoption of these behaviours according to the EI scores of the students.

Low EI students were more likely to engage in health-damaging behaviours,

'...I eat more, smoke...go out and get drunk...' (F3LoEI)

'...if I'm sort of stressed...I'll get on my bike and go mad...just going at stupid speeds...' (M5LoEI)

or have their sleeping pattern affected by stress,

'...usually I don't have a problem with sleep, but this week I'd say it's been a nightmare...' (M4LoEI)

whereas high EI students were able to judge that health-damaging behaviours did not help,

'...I used to smoke...I don't find that helps me calm down...' (F3HighEI)

Most interviewees recognised the importance of being organised in preventing and coping with stress. Some students found it difficult to juggle between the academic and personal demands, whereas others blamed the lack of time-management skills to the lack of time. A trend was detected in how students used organisation and time-management skills according to whether they had low or high EI.

Low EI students typically showed lack of organisation skills,

...I find it difficult to get 


\section{EDUCATION}

organised...when the College throws up things...and my life throws complications in, it all goes terribly to pot...the most delicately balanced bit of organisation I get going...all gets dashed to pieces...'

'...it's just the time...don't have enough...to do all the things that are required in the course...' (M4LoEI)

whereas high EI students were able to manage their time around unexpected events:

'...if there's a mishap...you have to like basically think it's not your fault...you just have to be organised in time management...' (M5HighEI)

\section{DISCUSSION}

This qualitative study reports on how dental undergraduates with low and high EI in one UK dental school experienced and coped with stress. The use of a qualitative design enabled the in-depth exploration of how male and female students from different years of study and with different levels of EI experienced and coped with their stress. Unlike quantitative research, this allowed a wide range of issues to be discussed and not just the predominant concerns. ${ }^{35}$ The key findings have been that high EI students reported stress coping skills that low EI students lacked, and low EI students were more likely to engage in health-damaging behaviours.

Results from the present study indicated that stress is experienced in emotional terms. When these emotions become overwhelming, the consequence is psychological distress or pathological anxiety. ${ }^{36}$ Although the present study was not designed to explore pathological anxiety in dental undergraduates, the strong emotional terms such as anger, frustration and hatred that were used to describe stress suggested that some of the students interviewed were experiencing pathological anxiety. This finding is consistent with the results of a survey carried out by NewburyBirch $^{7}$ in which $47 \%$ of second year and $67 \%$ of final year dental students were reported to suffer from possible pathological anxiety. In a survey of dental undergraduates in seven European dental schools, Humphris et al. ${ }^{8}$ reported a $36 \%$ prevalence of psychological morbidity and $22 \%$ of emotional exhaustion. Academic achievement may deteriorate as a result of emotional distress and clinical performance may worsen during patient care. Students' progress may be affected if they are unable to cope with their stress or manage the emotions evoked by their stressful experiences. There is a need to monitor students' emotional health and provide train- ing and support to ensure that they are able to cope with their stress.

A range of stress-coping strategies was identified in the present study. These were categorised into reflection and appraisal, social and interpersonal, lifestyle or behavioural adjustment, and organisation and time-management skills. The coping strategies identified were generally consistent with recommendations that are found in the literature. ${ }^{11}$ Students differed in the degree to which each coping strategy was adopted depending on their EI scores. Typically, high EI students reported a greater degree of reflection and appraisal, social and interpersonal skills, and organisation and time-management skills. Low EI students were more likely to engage in healthdamaging lifestyles or behaviours. Other researchers on EI have reported that high EI individuals are more able to appraise and use their emotions, and to possess social and interpersonal skills. ${ }^{18-20}$ Low EI individuals are less likely to be able to appraise the emotional repercussions of stressful events and make sense of them. Consequently, they engage in risk taking behaviours as a way of coping with the stress or avoiding it. The finding that dental undergraduates with different EI scores adopt different stress coping strategies has implications for the dental curriculum. In addition to training in the coping strategies identified, there is a need for interventions in the curriculum to enhance $\mathrm{EI}^{29}$ in dental undergraduates.

The coping strategies adopted by interviewees in the present study varied depending on their EI scores. High EI students were able to reflect on a stressful event, for example, seeing their first patient, appraise their emotions around the event and construct a positive analysis of the event. Low EI students tended to catastrophise on their stressful experiences and make negative inferences from them. Reflection and appraisal may be considered as an emotion-focussed coping style ${ }^{37}$ in which emotions evoked by stressful events are reflected upon and appraised to effect a positive reinterpretation of the event. Individuals who use this coping style tend to be less depressed and more satisfied with their lives. ${ }^{37}$

The interview transcripts also indicated that high EI students were able to use their social skills to access their social network in coping with their stress. They were able to use interpersonal skills to address stressful conflicts with colleagues and patients. Low EI students tended to procrastinate and withdraw from their social support network. Interpersonal skills are recommended as ideal skills in a good dentist $\mathrm{t}^{38}$ and discussing problems with other persons involved has been cited as a coping strategy for stress in practising dentists. ${ }^{11}$ Communication skills courses in the dental curriculum need to focus on developing interpersonal skills to enable students to cope better with their stress.

Adopting health-damaging lifestyles or behaviours was reported by low EI students in response to their experiences of stress. In contrast, high EI students were able to judge that such behaviours were not helpful. Health-damaging behaviours such as tobacco and alcohol consumption, use of drugs and medication are commonly reported in the literature as responses to stress in dental students ${ }^{39,7}$ and practising dentists. ${ }^{40,41}$ The present study is the first to link EI and health-damaging lifestyles or behaviours in dental undergraduates. Apart from causing harm to themselves, such habits may have implications on the students' perception of their role in health education on tobacco and alcohol consumption. Further research is needed to confirm quantitatively this association between EI and health-damaging lifestyles and behaviours, and their impact on dental students' role as future health care workers.

Most of the interviewees recognised that organisation and time-management were important in coping with stress. High EI students in the present study reported how they organised their activities and managed their time with confidence, whereas low EI students were tentative about how they structured their time. This finding supports other research which has indicated that time-management skills for dental students help them to cope better with their stress. ${ }^{9,12}$

\section{CONCLUSIONS}

Although stress coping strategies for dental students have frequently been recommended in the literature, the development of EI to enable them to cope better has not been proposed. During their undergraduate training, dental students often come into contact with their fellow students, tutors and patients in the context of a smallgroup, usually an intimate chair-side learning environment. In this environment EI is an important resource that enables students to manage stressful emotions in themselves and in those they work closely with. In managing the stressors in the dental environment, certain skills and behaviours are associated with different levels of EI. The results of the present study indicate that reflection and appraisal, social and interpersonal, and organisation and timemanagement skills are associated with high EI students, whereas health-damaging behaviours are associated with low EI students. An aim of dental education in the United Kingdom is to produce graduates who are competent, ethical and caring (GDC, 
2002). The development of other skills or intelligences, apart from EI, is therefore recognised. Future research needs to establish whether the enhancement of EI in dental students would lead to improved stress-coping and better physical and psychological health.

This study was supported by a grant from the Learning and Teaching Support Network (LTSN-01),

1. Garbee W H, Zucker S B, Selby G R. Perceived sources of stress among dental students. JADA 1980; 100: 853-857.

2. Grandy $T G$, Westerman $G H_{1}$ Combs $C E$, Turner $C H$. Perceptions of stress among third-year dental students. J Dent Educ 1989; 53: 718-721.

3. Newton J T, Baghaienaini F, Goodwin S R, Invest J Lubbock M, Marouf Saghakhanch N. Stress in dental school: a survey of students. Dent Update 1994; 21 : 162-164.

4. Peretz B, Rosenblum A, Zadik D. Stress levels and related variables among dental students in Jerusalem, Israel. Eur J Dent Educ 1997; 1: 162-166.

5. Steptoe A, Wardle J Pollard TM, Canaan L Davies GJ. Stress, social support and health-related behaviour: a study of smoking, alcohol consumption and physical exercise. J Psychosomatic Res 1996; 41: 171-181.

6. Naidu R S, Adams J S, Simeon D, Persad S. Sources of stress and psychological disturbance among dental students in the West Indies. J Dent Educ 2002; 66: 1021-1030

7. Newbury-Birch D, Lowry R J, Kamali F. The changing patterns of drinking, illicit drug use, stress, anxiety and depression in dental students in a UK dental school: a longitudinal study. Br DentJ 2002; 192: 646-649.

8. Humphris $\mathrm{G}$, Blinkhorn $\mathrm{A}$, Freeman $\mathrm{R}$, Gorter $\mathrm{R}$, Hoad Reddick G, Murtomaa H, O'Sullivan R, Splieth C. Psychological stress in undergraduate dental students: baseline results from seven European dental schools. Eur J Dent Educ 2002; 6: 22-29.

9. Tisdelle D A, Hansen D J, St Lawrence J S, Brown J C. Stress management training for dental students. $J$
Dent Educ 1984; 48: 196-202.

10. Litchfield N B. Stress-related problems of dentists. Int JPsychosomatics 1989; 36: 41-44.

11. Rankin J A, Harris M B. A comparison of stress and coping in male and female dentists. J Dent Practice Administration 1990; 7: 166-172.

12. Freeman R, Main J R, Burke FJ. Occupational stress and dentistry: theory and practice. Part II. Assessment and control. Br Dent J 1995; 178: 218-222.

13. Makikangas A, Kinnunen U. Psychosocial work stressors and well-being: self-esteem and optimism as moderators in a one year longitudinal sample. Personality and Individual Differences 2003; 35: 537-557.

14. Lo R. A longitudinal study of perceived level of stress, coping and self-esteem of undergraduate nursing students: an Australian case study. J Adv Nurs 2002; 39: 119-126.

15. McMullen B. Emotional intelligence. Br Med J 2003; 326: S19.

16. Goleman D. Emotional Intelligence: Why it can matter more than IO New York: Bantam, 1995.

17. Schutte N S, Malouff J M, Hall LE, Haggerty D J, Cooper J T, Golden C J, Dornheim L. Development and validation of a measure of emotional intelligence. Personality and individual differences 1998: $\mathbf{2 5}$ 167-177.

18. Petrides KV, Furnham A. On the dimensional structure of emotional intelligence. Personality and Individual Differences 2000; 29: 313-320.

19. Ciarrochi J, Deane FP, Anderson S. Emotiona intelligence moderates the relationship between stress and mental health. Personality and Individual Differences 2002: 32: 197-209.

20. Saklofske D H, Austin E J, Minski PS. Factor structure and validity of a trait emotional intelligence measure. Personality and Individual Differences 2003; 34: 707-721.

21. Gardner H. Intelligence Reframed. New York: Basi Books, 1999.

22. Carr D. Emotional Intelligence, PSE and Self Esteem: A cautionary Note. Pastoral care 2000: 27-33

23. Carrothers R M, Gregory S W Jr, Gallagher T J. Measuring emotional intelligence of medical school applicants. Acad Med 2000 : 75: 456-463.

24. Cadman C, Brewer J. Emotional intelligence: a vital prerequisite for recruitment in nursing. J Nurs Manag
2001; 9: 321-324

25. Elam C. Use of 'Emotional Intelligence' as One Measure of Medical School Applicants' Noncognitive Characteristics. Acad Med 2000: 75: 445-446.

26. Epstein R M, Hundert E M. Defining and assessing professional competence. JAMA 2002; 287: 226-235.

27. Wagner P J, Moseley G C, Grant M M, Gore J R, Owens C. Physicians' emotional intelligence and patient satisfaction. Fam Med 2002; 34: 750-754.

28. Watkin C. Developing Emotional Intelligence. Int Selection Assessment 2000: 8: 89-92.

29. Lynn A. The Emotional Intelligence Activity Book. New York: Amacon, 2002

30. Mays N, Pope C. Rigour and qualitative research. In Mays N. Pope C (eds) Qualitative Research in Health Care. Ch 2. London: BMJ, 1996.

31. Mays $\mathrm{N}$, Pope $\mathrm{C}$. Assessing quality in qualitative research. BrMed J 2000; 320: 50-52.

32. Britten N. Qualitative interviews in medical research. In Mays N, Pope C (eds) Qualitative Research in Health Care. Ch 2. London: BMJ, 1996

33. Pau A K H, Croucher R. Emotional intelligence and perceived stress in dental undergraduates. J Dent Educ 2003; 67: 1023-1028.

34. Ritchie J, Spencer L. Qualitative data analysis for applied policy research. In Bryman A and Burgess R G (eds) Analysing qualitative data. Ch 9. London: Routledge, 1994.

35. Greenhalgh T, Taylor R. Papers that go beyond numbers (qualitative research). BrMedJ 1997; 315 : 740-743.

36. Lundh L, Simonsson-Sarnecki, M. Alexithymia, Emotion, and Somatic Complaints. J Personality 2001 69: 483-510.

37. Nelson N G, Dell'Oliver C, Koch C, Buckler R. Stress, coping, and success among graduate students in clinical psychology. Psychol Rep 2001; 88: 759-767.

38. Kulich KR, Ryden O, Bengtsson H. A descriptive study of how dentists view their profession and the doctorpatient relationship. Acta Odontolo Scand 1998; 56: 206-209.

39. Underwood B, Fox K. A survey of alcohol and drug use among UK based dental undergraduates. Br Dent J 2000: 189: 314-317.

40. Forrest W R. Stresses and self-destructive behaviours of dentists. Dent Clin North Am 1978; 22: 361-371.

41. Kay E J, Scarrott D M. A survey of dental professionals health and well-being. Br DentJ 1997; 183: 340-345. 